\title{
Cardiac arrest in a young woman with the long QT syndrome and concomitant astemizole ingestion
}

\author{
Paul Broadhurst, Anthony W Nathan
}

\begin{abstract}
Ventricular fibrillation developed in a 19 year old woman taking the antihistamine astemizole. She was successfully resuscitated. QTe prolongation was found and persisted despite withdrawal of the drug. Aggravation of congenital long QTc syndrome by astemizole is postulated. More caution should be exercised with the use of this drug.
\end{abstract}

(Br Heart f 1993;70:469-470)

Astemizole is an antihistamine that is widely used to treat hay fever. It antagonises the effects of histamine at the $\mathrm{H}_{1}$ receptor site. It is one of several drugs of this type and is available without prescription. Over the past few years there have been several reports of serious ventricular arrhythmias in patients taking astemizole. ${ }^{1}$ All, however, have been the consequence of taking the drug in actual or suspected overdose. We report a case in which we postulate that astemizole contributed to the development of ventricular fibrillation in a young woman with what transpired to be congenital long QT syndrome.

\section{Case report}

A 19 year old woman was admitted after a cardiac arrest call from the nurses' swimming pool. She had been swimming and after becoming short of breath got out of the pool, fell back in and was then dragged out. Cardiopulmonary resuscitation was started and she was found to be in ventricular fibrillation. She was successfully defibrillated and over several days recovered completely without any neurological sequelae.

The cause of her arrest was initially unclear. Asthma was implicated at presentation, but she was easy to ventilate and subsequent pulmonary function tests were normal and a histamine provocation test was negative. She had been prescribed (by her general practitioner) and was taking astemizole $20 \mathrm{mg}$ per day, twice the maximum recommended dose, and had been doing so for several weeks because of hay fever. We were aware that this drug has been implicated in the genesis of ventricular arrhythmias.

Cardiological investigations included a series of electrocardiograms and during these it was noted that her QTc was persistently prolonged (table), though it did shorten with time. Astemizole has a long half-life (18-22 days), but even 2 months after the drug had been stopped the patient's QTc was still prolonged at $463 \mathrm{~ms}$ (upper limit of normal ${ }^{3}$ generally accepted to be $440 \mathrm{~ms}$ ). Both her father's and sister's QTc intervals were prolonged initially. They were both taking the antihistamine terfenadine at the time and subsequent electrocardiograms taken in the drug-free state showed a QTc of $435 \mathrm{~ms}$ (the upper limit of normal) in the sister though QTc was still slightly prolonged in the father. There was no family history of syncope or sudden death and there were no hearing problems in any family member. Echocardiography, cardiac catherisation and electrophysiological investigation were carried out in the patient. The results of these tests were unremarkable. We concluded therefore that our patient and her father both had the long QT or Romano-Ward syndrome.

The patient was discharged on atenolol 50 mg twice daily and was well 6 months later. She takes beclomethasone intranasally for her hay fever and both she and her family have been warned not to take antihistamines.

\section{Discussion}

This case illustrates several interesting and important points about the cardiac effects of antihistamines, particularly in the long QT syndrome. The increasing number of serious rhythm disturbances reported with both terfenadine and astemizole has led to a warning

\begin{tabular}{llll}
\multicolumn{4}{l}{$Q T, R R$, and $Q T c$ intervals in the patient and her family } \\
\hline Subject & $Q T(m s)$ & $R R(m s)$ & $Q T c(m s)$ \\
\hline Patient on day: & & & \\
1 & 420 & 740 & 488 \\
4 & 540 & 940 & 557 \\
7 & 540 & 1090 & 519 \\
11 & 425 & 890 & 452 \\
17 & 390 & 765 & 448 \\
19 & 370 & 835 & 406 \\
20 & 410 & 805 & 456 \\
& & & \\
Father & 445 & 910 & 468 \\
Off terfenadine & 440 & 920 & 459 \\
Mother & 350 & 690 & 412 \\
Sister & 400 & 640 & 500 \\
Off terfenadine & 410 & 890 & 435 \\
\hline
\end{tabular}

QTc is the QT interval corrected for heart rate using Bazett's formula. ${ }^{2}$ The intervals of the patient on the days after the admission are also shown. 
being issued by the Committee on Safety of Medicines. ${ }^{1}$ When these drugs are taken in deliberate overdose the risks are clear but it seems that drugs that interfere with the metabolism of these antihistamines also pose a risk. ${ }^{4}$ The administration of astemizole in twice the recommended dosage in our patient with underlying QT interval prolongation probably predisposed her to ventricular fibrillation: periods of sympathetic activation such as occur with exercise (for example, swimming) are also recognised as a precipitating factor. ${ }^{5}$ Furthermore in another family member the administration of terfenadine produced QTc prolongation that was not apparent in the drug free state. The cardiac electrophysiological effects of antihistamines have not been described, though in a small group of volunteers QT prolongation did not occur when astemizole was administered in therapeutic doses. ${ }^{6}$ Animal studies showed $\mathrm{H}_{1}$ histamine receptors within the heart. ${ }^{7}$ Blockage of these receptors might be expected to accelerate conduction in cardiac tissue in response to any endogenous histamine, for example to increase the speed of conduction within the atrioventricular node. It is difficult to see how such electrophysiological effects might be expected to produce QTc prolongation, which is generally accepted as being due to abnormal repolarisation.

From a practical point of view, we were left with the dilemma as to whether we should treat this young, very active woman with $\beta$ blockers, possibly for life. Because QTc prolongation persisted after withdrawal of the drug we felt that this approach was justified. Worldwide experience with $\beta$ blockers in this rare condition suggests that such treatment is beneficial in reducing the incidence of torsades de pointes, syncope, and sudden death. ${ }^{8}$

After our experience and that of others, it might be advisable to reappraise the general availability of antihistamines. We endorse the warning of both the manufacturers and the Committee on Safety of Medicines never to exceed the recommended dose.

1 Ventricular arrhythmias due to terfenadine and astemizole. Current Problems. London: Committee on Safety of Medicines 1992;35:1-2.

2 Bazett HC. An analysis of the time relations of electrocardiograms. Heart 1920;7:353-70.

3 Moss AJ, Schwartz PJ, Crampton RS, et al. The long QT syndrome. Circulation 1991;84:1136-44.

4 Pohjola-Sintonen S, Viitasalo M, Toivonen L, Neuvonen $P$. Torsades de pointes after terfenadine-itraconazole interaction. $B M F$ 1993;306:186.

5 Roden DM. The long QT syndrome and Torsades de Pointes: Basic and clinical aspects. In: El-Sherif N, Samet $\mathrm{P}$, eds. Cardiac pacing and electrophysiology. Philadelphia: WB Saunders, 1991;265-84

6 Craft TM, Vanden Bussche G, De Cree J, Griffiths JV. ECG studies with astemizole. Hum Exp Toxicol 1987;6: 527-8.

7 Levi R, Kuye JO. Pharmacological characterisation of cardiac histamine receptors: sensitivity to $\mathbf{H}_{1}$-receptor antagonists. Eur $¥$ Pharmacol 1974;27:330-8.

8 Moss AJ, Schwartz PJ, Crampton RS, Locati E, Carleen E. The long QT syndrome: a prospective international registry. Circulation 1985;71:17-21. 